\title{
Cytoreductive Surgery and Hyperthermic Intraperitoneal Chemotherapy for Gastric Cancer
}

\author{
Adriana C. Gamboa * and Joshua H. Winer \\ Division of Surgical Oncology, 1365B Clifton Road NE, Suite B4000, Atlanta, GA 30322, USA; jhwiner@emory.edu \\ * Correspondence: acgambo@emory.edu; Tel.: +404-778-3387
}

Received: 23 September 2019; Accepted: 24 October 2019; Published: 26 October 2019

check for updates

\begin{abstract}
The management of peritoneal metastases from gastric cancer origin has evolved considerably over the last three decades with the establishment of cytoreductive surgery (CRS) and hyperthermic intraperitoneal chemotherapy (HIPEC) as efficacious therapies in carefully selected patients. Other approaches such as the use of prophylactic/adjuvant HIPEC in patients who are considered high-risk and those with positive peritoneal cytology will benefit from additional data before being adopted into routine clinical practice. Lastly, there are new and emerging intraperitoneal chemotherapy techniques such as early post-operative intraperitoneal chemotherapy (EPIC) for residual microscopic disease, and pressurized intraperitoneal aerosolized chemotherapy (PIPAC) for patients with advanced unresectable peritoneal carcinomatosis, which are currently under evaluation in clinical trials. The following review outlines the natural history of gastric cancer, currently available neoadjuvant and adjuvant therapies for resectable disease, and existing evidence supporting various approaches to CRS and intraperitoneal chemotherapy.
\end{abstract}

Keywords: Cytoreductive surgery; intraperitoneal chemotherapy; peritoneal metastases; gastric cancer

\section{Introduction}

\subsection{Epidemiology and Natural History of Gastric Cancer}

Gastric cancer is the fifth most common cancer in the United States with an estimated 952,000 incident cases per year [1]. There is widespread geographic variation in its prevalence, with the highest rates occurring in East Asia, South/Central America, and Eastern Europe [2]. Although recent advances and efforts in screening have allowed earlier detection in more endemic areas, most patients are diagnosed at advanced stages, and as such, gastric cancer remains the third leading cause of cancer-related deaths globally [1].

In the United States, approximately $28 \%$ of patients present with localized disease for whom the mainstay of treatment remains curative-intent gastrectomy with extended (D2) lymphadenectomy [3]. The remainder of patients will present with local-regional disease or distant spread. Since the publication of the seventh edition of the American Joint Committee on Cancer (AJCC) staging manual, positive peritoneal cytology is classified as M1 disease, even in the absence of visible peritoneal implants, based on previous studies demonstrating that positive cytology is a strong, independent pre-operative predictor of recurrence and survival in patients undergoing R0 resection for gastric cancer $[4,5]$. The incidence of cytology-positive disease at presentation ranges widely depending on T-stage but has been reported to be as high as 30\%, with gross peritoneal carcinomatosis present in almost 20\% [6]. Furthermore, even after resection and extended lymphadenectomy, studies of recurrence patterns demonstrate that gastric cancer has the highest rate of peritoneal recurrence of all digestive cancers, with a rate approaching $40 \%-60 \%$ after curative gastrectomy, rising to $80 \%$ for those 
with tumor-positive peritoneal cytology [7-11]. Accordingly, progressive peritoneal carcinomatosis accounts for nearly $60 \%$ of deaths from gastric cancer [12].

Historically, the survival rate for gastric carcinoma patients with peritoneal carcinomatosis has been poor, ranging from 2.2 to 8.8 months and no survival at 5 years [13]. Quality and length of life is further worsened by complications such as bowel obstruction, malignant ascites, malnutrition and cachexia, which occur commonly in the setting of peritoneal disease [14,15]. Currently, as peritoneal carcinomatosis is considered a variant of the systemic spread of disease, the standard recommendation for patients with gastric cancer metastatic to the peritoneum is systemic chemotherapy or best supportive care [16]. However, patient-specific novel strategies are being developed to improve the outcome of gastric cancer patients with advanced stage disease. The purpose of this review is to analyze the existing body of literature regarding multimodal treatment strategies for prevention and treatment of peritoneal carcinomatosis from gastric cancer.

\subsection{Multimodal Treatment of Resectable Gastric Cancer}

Although there is no consensus on the optimal treatment approach for resectable gastric cancer, given that local-regional failure is common following curative-intent surgery for gastric cancer and that the pattern of local-regional failure includes both the gastric remnant, the bed of resection, and regional nodal basins, multimodal therapy is paramount and studies have repeatedly validated that combined therapy significantly increases survival in gastric cancer patients with local-regional disease $[17,18]$. While no universal standard-of-care for the treatment gastric cancer exists, local recommendations are generally followed according to the results of the phase III trials that have been conducted in those areas. Therefore, while perioperative chemotherapy is the preferred treatment strategy for primary gastric cancer in many European countries and the United States, adjuvant chemotherapy is the standard practice in Eastern Asian countries. The therapeutic options for patients with peritoneal metastases, however, are less well-defined, and current treatment recommendations remain controversial.

The following sections highlight current standard-of-care practices for resectable gastric cancer including perioperative and adjuvant systemic chemotherapy, as well as possible therapeutic strategies for the prevention and/or treatment of peritoneal metastases including cytoreductive surgery (CRS) and perioperative chemotherapy which may include neoadjuvant intraperitoneal and systemic chemotherapy (NIPS), hyperthermic intraperitoneal chemotherapy (HIPEC) and/or early post-operative intraperitoneal chemotherapy (EPIC).

\subsection{Perioperative Chemotherapy for Resectable Gastric Cancer}

Peri-operative chemotherapy is the preferred approach for patients with localized, resectable disease in the United States and Europe based on data from two landmark trials in which peri-operative chemotherapy in combination with resection resulted in improved long-term outcomes $[19,20]$. In the seminal 2006 Medical Research Council Adjuvant Gastric Infusional Chemotherapy (MAGIC) trial, 503 patients with resectable adenocarcinoma of the stomach, esophagogastric junction, or lower esophagus were randomized to surgery with three months of peri-operative chemotherapy with epirubicin, cisplatin and fluorouracil (ECF) or surgery alone. Overall survival (OS) as well as progression-free survival (PFS) were significantly improved in patients who received peri-operative chemotherapy compared with patients treated by surgery alone ( $p=0.009$ and $p<0.001$, respectively). The 5 -year OS rate was $36 \%$ for in the peri-operative chemotherapy arm versus $23 \%$ for in the surgery only arm. Based on these results, the MAGIC regimen was the preferred peri-operative chemotherapy option for nearly a decade [19]. Recently, the 2019 German phase II/III FLOT-4 trial established the superiority of a peri-operative taxane-based regimen with fluorouracil and leucovorin, oxaliplatin, and docetaxel (FLOT) over peri-operative epirubicin, cisplatin and a fluoropyrimidine or capecitabine $(\mathrm{ECF} / \mathrm{ECX})$ in patients with locally advanced, resectable gastric or gastro-esophageal junction adenocarcinoma. The FLOT regimen significantly improved median survival (FLOT: 50 months 
vs ECF/ECX: 35 months), and led to a higher number of R0 resections (FLOT: 84\% vs. ECF/ECX: $77 \%)[20]$.

The benefit of neoadjuvant chemotherapy was further established by a Cochrane meta-analysis which reviewed 14 randomized controlled trials investigating the benefit of pre/peri-operative chemotherapy for patients with gastroesophageal adenocarcinoma and found that peri-operative chemotherapy was associated with significantly longer OS (hazard ratio (HR) $0.81,95 \%$ confidence interval (CI) $0.73-0.89, p<0.0001)$ compared to surgery alone [21]. As these findings have not been replicated in East Asia, neoadjuvant chemotherapy in that region is reserved for patients with locally advanced, marginally resectable gastric cancer, para-aortic and/or bulky nodal disease, and serosa-positive gastric cancer [22].

\subsection{Adjuvant Chemotherapy and Chemoradiation}

In East Asian countries, adjuvant chemotherapy following curative-intent resection without any neoadjuvant therapy is the standard-of-care based on Japanese and Korean trials which showed a clear benefit of adjuvant therapy for stage II or III gastric cancer using S1 (a polypharmaceutic, fluoropyrimidine derivative that combines tegafur with two modulators, gimeracil, and oteracil) administered for one year after surgery or intravenous capecitabine and oxaliplatin (XELOX) [23]. In a 2007 Japanese randomized controlled trial, 529 patients were randomized to D2 gastrectomy followed by S1 beginning within 6 weeks of surgery and continuing for one year, while 530 patients were randomized to D2 gastrectomy alone. The three-year OS was $80 \%$ in the $\mathrm{S} 1$ group and $70 \%$ in the surgery group $[24,25]$. Subsequently, the capecitabine and oxaliplatin adjuvant study in stomach cancer (CLASSIC) phase III randomized controlled trial undertaken in 37 centers in South Korea, China, and Taiwan randomized 1035 patients to adjuvant chemotherapy with capecitabine plus oxaliplatin or surgery alone. There was a 15\% improvement in 3-year disease-free survival (DFS) in the chemotherapy and surgery group (HR $0.56,95 \%$ CI $0.44-0.72, p<0.0001)$ [26]. A subsequent analysis at 5-year follow-up demonstrated a 9\% improvement in OS in the adjuvant capecitabine and oxaliplatin group versus the observation group [27]. Recently, a large 2010 meta-analysis that combined European and Asian data from 17 randomized controlled trials $(n=3838)$ with a median follow-up longer than 7 years, demonstrated an OS benefit of $5.8 \%$ at 5 years with post-operative adjuvant fluoropyrimidine-based chemotherapy when compared with surgery alone [28]. Independent European trials of adjuvant chemotherapy have failed to demonstrate similar results and shown no difference between post-operative chemotherapy and surgery alone with D1 lymphadenectomy [29-31]. Some of these differences are attributed to marked disparities between the East and the West in both tumor biology -intestinal type and distal stomach location in Asia, versus more diffuse tumors located in the proximal stomach and gastroesophageal junction in the West-and historical surgical practices [32].

The landmark phase II Intergroup-0116 (INT-0116) trial conducted in the United States is the only randomized control trial to support adjuvant chemoradiation for gastric cancer. In this trial, 556 patients with stage IB-IV, M0 gastric cancer were randomized after surgical resection to receive post-operative chemotherapy with 5-FU and leucovorin plus chemoradiation or no additional treatment. After a median follow-up of 5 years, median OS in the surgery-only group was 27 months compared to 36 months in the post-operative chemotherapy plus chemoradiation group $(p=0.005)$ [33]. As only $10 \%$ of the patients underwent a D2 lymphadenectomy, the results of the trial are limited as they are only applicable to patients who undergo a D0 or D1 lymph node dissection. This limitation has led to the criticism that chemoradiation was compensating for inadequate surgical clearance of involved lymph nodes thus resulting in improved survival.

The first trial to assess the role of adjuvant chemoradiation after curative-intent gastric cancer resection and D2 lymphadenectomy was the Korean Adjuvant Chemoradiation Therapy in Stomach Cancer (ARTIST) trial where 458 patients with stage IB-IV gastric cancer were randomized to either six cycles of adjuvant capecitabine-cisplatin or to two cycles of capecitabine-cisplatin before and after 
capecitabine-based chemoradiation. This study demonstrated no difference in 3-year DFS between arms $(78.2 \%$ vs. $74.2 \%, p=0.09)$. Importantly, in the subgroup of patients $(n=396)$ with positive lymph nodes at the time of surgery, patients assigned to the chemotherapy and chemoradiation arm had a slightly improved 3-year DFS when compared to those who received chemotherapy alone $(77.5 \%$ vs. $72.3 \%, p=0.04$ ) [34]. Unfortunately, the small sample size within each stage precluded a subgroup stage-specific analysis. Additionally, it is unclear whether the ARTIST data can be applied to Western populations as results from Asian gastric cancer trials have consistently shown improved outcomes compared to Western studies. We currently await the results of the Korean ARTIST-II trial which seeks to compare S1 vs. S1/Oxaliplatin with and without radiotherapy for completely resected gastric adenocarcinoma with D2 lymphadenectomy (NCT01761461).

Several current studies have been designed to further address the optimal sequencing of multimodality therapy in gastric cancer. The Dutch CRITICS trial is comparing pre-operative chemotherapy alone with epirubicin, cisplatin, and capecitabine (ECX) followed by surgery and post-operative ECX alone versus pre-operative ECX followed by surgery and post-operative chemoradiation (NCT00407186) [35]. TOPGEAR is an Australasian, Canadian, and European study evaluating perioperative ECF chemotherapy alone versus perioperative ECF and pre-operative chemoradiation (NCT01924819).

Currently, given the results from the INT-0116 and the ARTIST trials, adjuvant chemoradiation is only recommended for patients who receive less than a D2 lymph node dissection while patients who receive a D2 dissection should be treated with post-operative chemotherapy alone. Unfortunately, chemotherapy and radiotherapy have not shown significant survival advantage as adjuvant treatment for patients with high risk of peritoneal carcinomatosis and locoregional recurrence is still a considerable problem $[36,37]$.

\section{Approach to Cytoreductive Surgery and Hyperthermic Intraperitoneal Chemotherapy}

In patients with peritoneal metastases, systemic chemotherapy alone has had disappointing results. In 1989, Preusser et al. demonstrated that patients with advanced gastric cancer can be treated with an aggressive systemic chemotherapy regimen with a $50 \%$ response rate, but was not able to demonstrate a similar response rate in in patients with peritoneal carcinomatosis [38]. Similarly, in 1991, Ajani et al. implemented peri-operative chemotherapy with etoposide, 5-fluorouracil, and cisplatin and found that peritoneal carcinomatosis was the most common reason for treatment failure [39]. Systemic chemotherapy alone is, therefore, not a recommended management plan for patients with peritoneal carcinomatosis. Recently, the use of a multimodality treatment strategy including CRS combined with heated intraperitoneal chemotherapy (HIPEC) has led to promising results in selected patients with peritoneal carcinomatosis of gastric origin. The following section outlines contemporary approaches to CRS and HIPEC in gastric cancer, the currently accepted indications for implementation of this treatment strategy, and other emerging options.

\subsection{Role of Cytoreductive Surgery and Hyperthermic Intraperitoneal Chemotherapy (HIPEC) in Peritoneal Cancers}

For patients at high risk for peritoneal carcinomatosis from gastric cancer, treatment remains limited as neither neoadjuvant nor adjuvant treatment approaches have been shown to decrease the progression to peritoneal carcinomatosis. Importantly systemic therapies have limited effects on peritoneal carcinomatosis likely due to the blood-peritoneal barrier consisting of stromal tissue between mesothelial cells and sub-mesothelial blood capillaries [12]. The resulting median survival for these patients is, therefore, as low as 5 months [40].

Multimodal therapeutic approaches combining CRS and peritonectomy with peri-operative intraperitoneal chemotherapy have emerged over the last four decades after this approach was first proposed in 1980 by Spratt in canine models, with the rationale being that it treats the most common pattern of failure that occurs after gastric cancer surgery [41]. The technique of CRS followed by HIPEC 
was further advanced by Sugarbaker in the 1990s [42]. The foundation of both of these practices can be explained by Gompertzian cellular kinetics which postulate that in the initial stages, tumor cell growth is exponential. As the tumor enlarges, its blood supply diminishes thus slowing down tumor growth. Tumor debulking thereby allows the cells to re-enter the proliferative phase of the cell cycle, potentially becoming more sensitive to anti-neoplastic agents. The importance of debulking by CRS is further underscored by the concept that intraperitoneal chemotherapy penetrates the peritoneal nodule by simple diffusion and has limited penetration of only $2-3 \mathrm{~mm}$ of tissue $[36,43,44]$. Hyperthermia between $39{ }^{\circ} \mathrm{C}$ and $43{ }^{\circ} \mathrm{C}$ additionally enhances the chemosensitivity of tumor cells to the cytotoxic agents and increases the effectiveness of certain agents (mitomycin $C$, cisplatin, oxaliplatin), while achieving drug concentrations that are up to 20 times higher compared to plasma levels and minimizing systemic toxicity due to the blood peritoneal barrier $[13,45]$.

The importance of patient selection for CRS and intraperitoneal chemotherapy cannot be overstated as a large number of patients with gastric peritoneal metastases will not benefit from CRS and HIPEC due to the extent of disease. Accurate pre-operative imaging not only assists in planning cytoreduction, but also prevents an unwarranted laparotomy in patients who have unresectable disease. The extent of peritoneal metastases as measured by Sugarbaker's peritoneal cancer index (PCI) significantly influences completeness of cytoreduction and subsequent survival [46]. The current literature for the use of HIPEC for peritoneal metastases of gastric cancer origin has significant variation related to treatment intent, stage of disease, surgical technique, and intraperitoneal chemotherapy agent utilized. The following sections outline some of the important advances that have been made over the past four decades in each of these areas for the treatment of gastric cancer.

\subsection{Drugs Used in HIPEC}

Multiple drugs have been used in HIPEC for gastric cancer and there is currently no consensus regarding the optimal drug regimen or dosing strategy. Mitomycin C, cisplatin and taxanes are the most commonly used agents as they display the characteristics of an ideal drug including proven systemic activity, synergistic activity with hyperthermia, and concentration-related toxicity. Mitomycin $\mathrm{C}$ is an alkylating tumor antibiotic and was the first drug used as monotherapy for HIPEC. It is usually given in a dose of $15 \mathrm{mg} / \mathrm{m}^{2}$ for 90 minutes [7,47]. The most common regimen consists of $40 \mathrm{mg}$ mitomycin C for 90-120 minutes. Platinum-based alkylating agents such as cisplatin and oxaliplatin are commonly employed, typically in combination with mitomycin C [48]. Cisplatin has been given in doses ranging from 50 to $200 \mathrm{mg} / \mathrm{m}^{2}$ with perfusion time between 60 and 90 minutes [49]. Oxaliplatin is usually dosed at $460 \mathrm{mg} / \mathrm{m}^{2}$ for either 30 or 60 minutes as it is rapidly taken up by tumor tissue [50]. These two agents are also generally administered with a metal binding agent such as sodium thiosulfate to prevent renal toxicity. Additionally, due to synergistic effect of oxaliplatin with 5-FU, oxaliplatin can be administered with concurrent intravenous 5-FU and leucovorin as part of bidirectional therapy either just prior to, or during, hyperthermic intraperitoneal chemotherapy [51].

\subsection{Intraperitoneal Chemotherapy as Neoadjuvant Approach}

The first study to consider the use of HIPEC as a neoadjuvant approach prior to gastrectomy in patients with positive peritoneal cytology or low-volume peritoneal carcinomatosis was published in 2017 by Badgwell et al. In this single-arm phase II trial, 19 patients received laparoscopic HIPEC with a combination of mitomycin C $30 \mathrm{mg}$ and cisplatin $200 \mathrm{mg}$. Approximately half of the patients $(48 \%)$ received two to five laparoscopic procedures. After the final HIPEC, seven patients had negative peritoneal cytology and no peritoneal carcinomatosis, and five of these patients underwent definitive surgery. For these five patients, the median OS from date of resection was 29 months while the median OS from the date of diagnosis of metastatic disease for the whole group was 30.2 months. Although this was limited by a small sample size, results demonstrate the feasibility of integrating neoadjuvant HIPEC into the therapeutic armamentarium for gastric cancer [52]. Additionally, this study established laparoscopy as a potential tool for evaluating extent of peritoneal disease below the 
threshold of imaging modalities [53]. This same group further demonstrated the safety of laparoscopy for gastric HIPEC in a 2019 retrospective study of 77 laparoscopic HIPEC procedures in 44 patients with peritoneal carcinomatosis or peritoneal positive cytology. In this study, there were no conversions to laparotomy and median length of stay was two days. Importantly, $25 \%$ of patients underwent secondary gastrectomy following resolution of positive peritoneal cytology [54].

In 2006, a new bidirectional chemotherapy therapeutic strategy for patients with peritoneal carcinomatosis from gastric cancer was proposed which includes neoadjuvant intraperitoneal and systemic chemotherapy (NIPS) [55]. The rationale for this technique is to target peritoneal carcinomatosis via the systemic circulation and by diffusion from within the peritoneal cavity to enable a complete cytoreduction. In the 2006 study by Yonemura et al., patients with histologically or cytologically proven peritoneal carcinomatosis from gastric adenocarcinoma underwent placement of a peritoneal port system which allowed infusion of $400 \mathrm{mg}$ of docetaxel and $150 \mathrm{mg}$ of carboplatin with simultaneous intravenous infusion of methotrexate and 5-FU. A minimum of two cycles and up to six cycles of NIPS were used prior to cytoreduction. Treatment resulted in negative peritoneal cytology in $56 \%$ of patients and those who received a complete resection had a median survival of 20.4 months compared to 14.4 months in all patients [55]. In a subsequent 2012 study by Yonemura et al., 96 patients with histologically or cytologically proven peritoneal carcinomatosis underwent similar treatment with intraperitoneal Taxotere and cisplatin with infusions on days 1, 8, and 15 in conjunction with oral S1 for 21 days. This cycle was performed twice prior to surgery. Among all the enrolled patients, 82 were eligible for CRS, gastrectomy, peritonectomy and D2 lymphadenectomy. Complete pathologic response was achieved in $36.8 \%$, and complete cytoreduction (CC-0) in 70\%. Importantly, grade 3 and 4 complications were reported in $10 \%$, which is approximately the same as reported for CRS and HIPEC in the absence of NIPS. Median survival of patients who were able to undergo CRS was 14.4 months compared to 9.0 months in patients who were not able to undergo CRS $(p=0.032)$ [12].

In 2014, Canbay et al. assessed early- and long-term outcomes of NIPS in 194 patients with positive peritoneal cytology. After induction treatment, $78 \%$ of patients who showed negative cytology underwent CRS and HIPEC. Similar to the 2012 study by Yonemura et al., complete response was achieved in $24 \%$, and complete cytoreduction was achieved in $68 \%$. For those who underwent definitive surgery, median survival was 15.8 months compared to 7.5 months for patients who did not undergo surgery due to persistent positive cytology or peritoneal deposits $(p<0.001)$. Complete cytoreduction resulted in a significantly higher median survival of 20.5 months compared to 10.9 months for those who underwent attempted debulking. Post-operative complications occurred in $24 \%$, and post-operative mortality rate was $4 \%$. Multivariable analysis identified pathologic response, low tumor burden (PCI $\leq 6)$, and completeness of cytoreduction (CC-0/CC-1; all $p=0.001$ ) as independent predictors for a better prognosis. Notably, this study also showed that 78 patients with ascites had improvement in their symptoms thus further establishing the role of NIPS as a palliative technique [56]. As evidenced here, there are currently several regimens used for NIPS but none have been compared in clinical trials.

Based on these data, NIPS should be considered in gastric cancer patients with low-volume peritoneal metastases $(\mathrm{PCI} \leq 6)$ or symptomatic ascites. Clinical trials are needed to further establish this approach to CRS and HIPEC and none have occurred to date.

\subsection{HIPEC as Prophylactic/Adjuvant Approach}

Given the negative prognostic value of positive peritoneal cytology and peritoneal carcinomatosis in gastric cancer, it is imperative to prevent peritoneal recurrence after radical surgery in patients at high-risk. One of the most recent therapeutic approaches for patients who are considered high-risk for peritoneal recurrence is the administration of intraperitoneal adjuvant chemotherapy soon after curative-intent resection. The benefit of using HIPEC as an adjuvant treatment for locally advanced but resectable gastric cancer without pre-operatively confirmed peritoneal disease has been reported in several phase II clinical trials from Japan and China and a single meta-analysis. 
In 1988, Koga et al. were the first to report the long-term benefit in survival of adding HIPEC to curative gastrectomy (3-year survival of $74 \%$ with HIPEC and $53 \%$ without HIPEC, $p<0.04$ ) [47]. In 2001, Yonemura et al. randomized 139 patients with intraoperative findings of serosal involvement to surgery and HIPEC with mitomycin and cisplatin, surgery and intraperitoneal chemotherapy without hyperthermia, or surgery alone. Overall 5-year survival rate was $61 \%$ in the HIPEC group as opposed to $43 \%$ and $42 \%$ in the other two groups [50]. Also in 2001, Kim et al. performed a prospective controlled study for 52 patients who were selected to undergo surgery and HIPEC with mitomycin $C$ versus 51 patients who underwent surgery alone. 5-year survival rate was significantly higher in the surgery and HIPEC group (59\%) compared to surgery alone $(44 \%)$ when stage IV (peritoneal carcinomatosis) patients were excluded ( $p=0.04)$ [57].

The remaining studies which have sought to address the role of HIPEC as a prophylactic/adjuvant therapeutic approach are summarized in Table 1. Recently, a few systematic reviews and meta-analyses have also sought to understand the benefit of adjuvant HIPEC. A 2007 meta-analysis by Yan et al. included 13 studies in which patients with locally advanced gastric cancer were randomized to receive surgery combined with intraperitoneal chemotherapy versus surgery alone. There was a survival benefit associated with HIPEC (HR 0.60, 95\% CI 0.43-0.83, $p=0.002$ ) or HIPEC with EPIC (HR $0.45,95 \%$ CI $0.29-0.68, p=0.0002$ ) as well as a small benefit with normothermic intraoperative intraperitoneal chemotherapy, but no significant improvement in survival with EPIC alone or delayed post-operative intraperitoneal chemotherapy [58]. Similarly, Coccolini et al. performed a systematic review in 2014 to evaluate the effects of intraperitoneal chemotherapy in patients with advanced gastric cancer with or without peritoneal carcinomatosis. Results demonstrated that 1-, 2- and 3-year OS was improved by the intraperitoneal chemotherapy in all included patients and in patients with locoregional nodal metastasis or serosal infiltration [59]. A recent 2018 meta-analysis by Desiderio et al. included 11 randomized controlled trials and 21 studies comprising a total of 2520 patients comparing surgery with HIPEC and standard surgical management for the treatment of advanced stage gastric cancer with and without peritoneal carcinomatosis. Analysis demonstrated a significant 3-year and 5-year survival benefit to HIPEC compared to surgery alone (3-year: risk ratio $[R R]=0.71,95 \%$ CI $0.53-0.96$, $p=0.03$; 5-year: $\mathrm{RR}=0.82,95 \%$ CI 0.70-0.96, $p=0.01$ ) [60]. Despite the inclusion of some patients with peritoneal involvement in these studies and the heterogeneity with respect to the drugs used, results demonstrate that long-term outcomes can be improved with intraoperative peritoneal chemotherapy in the adjuvant/prophylactic setting. Ultimately, these analyses cannot be used to determine the best regimen of intraperitoneal chemotherapy for advanced gastric cancer. Additionally, several questions remain to be answered including the optimal choice of agent, dosage and duration of treatment.

Table 1. Prospective or randomized controlled studies evaluating the effect of hyperthermic intraperitoneal chemotherapy (HIPEC) as prophylactic/adjuvant approach.

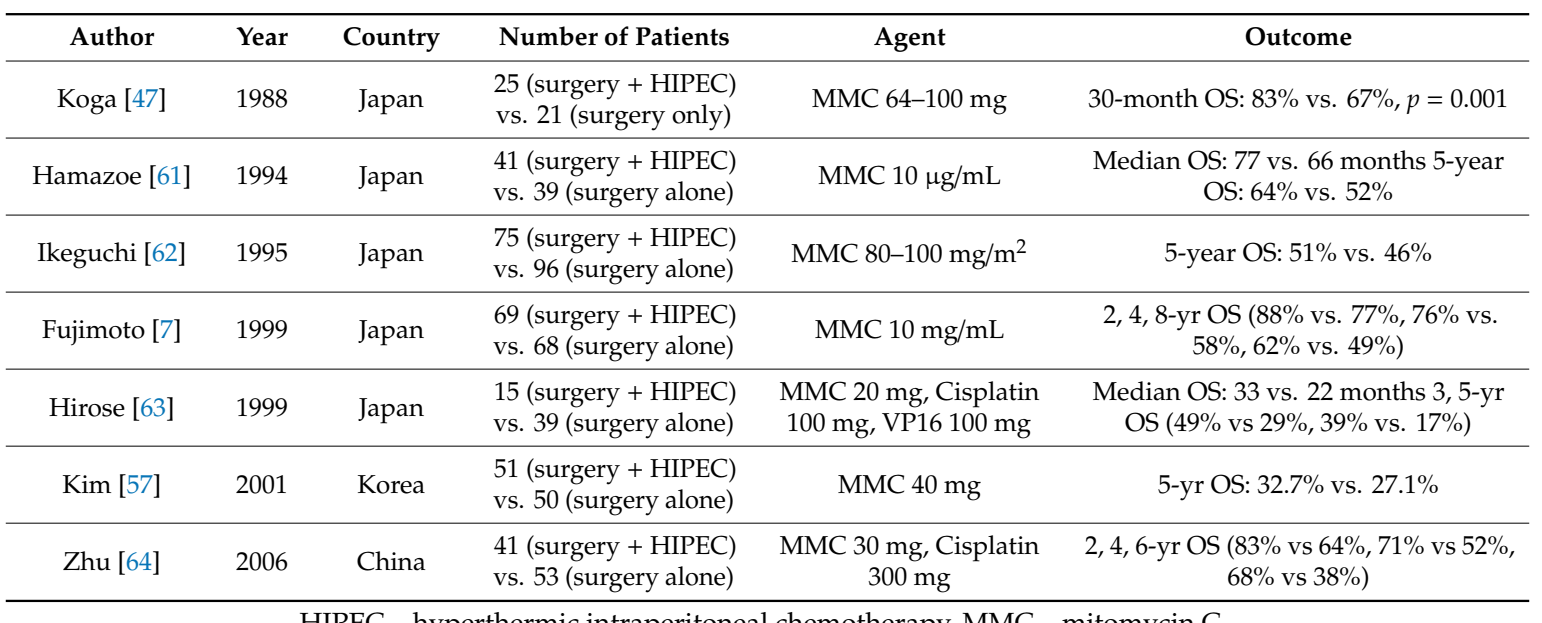

HIPEC—-hyperthermic intraperitoneal chemotherapy, MMC—-mitomycin C. 


\subsection{HIPEC with Curative Intent for Cytology Positive Peritoneal Carcinomatosis}

To date, no trials have been conducted to evaluate the effect of HIPEC on cytology-only positive peritoneal carcinomatosis. A prospective phase III multi-institutional randomized controlled trial is currently ongoing in France to compare 5-year OS of patients with gastric cancer involving the serosa and/or lymph node involvement and/or with positive cytology at peritoneal washing who undergo curative gastrectomy and D2 resection with and without HIPEC with Oxaliplatin. Secondary end points include DFS, morbidity, pattern of recurrence, and quality of life (GASTRICHIP, NCT01882933) [9].

\subsection{HIPEC with Curative Intent for Macroscopic Peritoneal Carcinomatosis}

The majority of the literature regarding the benefit of CRS and HIPEC in gastric cancer has included patients with macroscopic peritoneal disease (Table 2). Some of these studies, while initially designed to evaluate HIPEC in the adjuvant/prophylactic setting in patients undergoing a potentially curative resection, include separate analyses of patients that were unexpectedly found to be stage IV at operation but still underwent resection of serosal deposits followed by HIPEC. So far, however, only a few randomized clinical trials have been conducted to support such a treatment strategy. The initial trials conducted in 1983 through 1993 included few patients with stage IV disease [7,50,61]. A 2007 meta-analysis summarized results from these early trials and found a significant survival improvement in favor of surgery and HIPEC compared with surgery alone (HR 0.60, 95\% CI 0.43-083, $p=0.002$ ) [58]. 
Table 2. Prospective or Randomized controlled studies evaluating the effect of HIPEC in established peritoneal carcinomatosis.

\begin{tabular}{|c|c|c|c|c|c|c|}
\hline Author & Year & Country & Number of Patients & Agent & Duration (min) & Outcome \\
\hline Fujimoto [65] & 1990 & Japan & $\begin{array}{l}20 \text { (CRS + HIPEC) vs. } \\
7 \text { (CRS only) }\end{array}$ & MMC $10 \mu \mathrm{g} / \mathrm{mL}$ & 120 & 6-mo survival: $94 \%$ vs. $57 \%, p=0.001$ \\
\hline Yonemura [66] & 1991 & Japan & 41 & MMC $5 \mu \mathrm{g} / \mathrm{mL}$ Cisplatin $30 \mu \mathrm{g} / \mathrm{mL}$ & $40-60$ & Median survival: 14.5 mo 3-yr survival: $28.5 \%$ \\
\hline Yonemura [67] & 1996 & Japan & 83 (surgery + HIPEC) & $\begin{array}{l}\text { MMC } 30 \text { mg Cisplatin } 300 \text { mg Etoposide } \\
\qquad 150 \mathrm{mg}\end{array}$ & 60 & $\begin{array}{c}\text { 5-yr survival (overall: } 11 \% \text {, CCR0/1: } 17 \% \text {, } \\
\text { CCR2: } 2 \% \text { ) }\end{array}$ \\
\hline Fujimoto [68] & 1997 & Japan & $\begin{array}{l}48 \text { (CRS + HIPEC) vs. } \\
18 \text { (CRS only) }\end{array}$ & $\mathrm{MMC} 10 \mu \mathrm{g} / \mathrm{mL}$ & 120 & $\begin{array}{c}1,3,5,8-y r \text { survival (CRS + HIPEC vs. CRS: } \\
54 \% \text { vs. } 11 \%, 42 \% \text { vs. } 0 \%, 31 \% \text { vs. } 0 \%, 25 \% \text { vs } \\
0 \% ; p=0.001)\end{array}$ \\
\hline Glehen [69] & 2004 & France & 49 (CRS + HIPEC) & MMC 40-60 mg & 90 & $\begin{array}{l}\text { Median survival (overall: } 10.3 \mathrm{mo} \text {; CCR0/1 vs } \\
\text { CCR2: } 21.3 \text { vs. } 6.6 \text { mo, } p<0.001 \text { ) }\end{array}$ \\
\hline Yang [70] & 2010 & China & 28 (CRS + HIPEC) & MMC 30 mg Cisplatin $120 \mathrm{mg}$ & $90-120$ & $\begin{array}{l}\text { 2-yr survival: } 43 \% \text { Median survival }(\mathrm{PCI} \leq 20 \\
\text { vs } \mathrm{PCI}>20) \text { : } 27.7 \text { vs. } 6.4 \mathrm{mo}, p=0.0001\end{array}$ \\
\hline Yang [71] & 2011 & China & $\begin{array}{l}34 \text { (CRS + HIPEC) vs. } \\
34 \text { (CRS only) }\end{array}$ & MMC 30 mg Cisplatin $120 \mathrm{mg}$ & $60-90$ & $\begin{array}{c}\text { Median survival (CRS + HIPEC vs. CRS): } 12 \\
\text { vs. } 6.5 \text { mo, } p=0.02\end{array}$ \\
\hline Magge [72] & 2014 & USA & 23 (CRS + HIPEC) & MMC $40 \mathrm{mg}$ & 100 & Median survival: 9.5 mo 3-yr survival: $18 \%$ \\
\hline
\end{tabular}

CRS-cytoreductive surgery, HIPEC-hyperthermic intraperitoneal chemotherapy, MMC-mitomycin C. 
In 2004, Glehen et al. conducted a prospective trial with 49 patients with peritoneal carcinomatosis who underwent HIPEC with 40-60 mg of mitomycin C. The overall 1-, 2- and 5-year survival rates were $48 \%, 20 \%$, and $16 \%$, respectively. Significant independent predictors of worse survival were pre-operative malignant ascites and CCR-2 (diameter of residual nodules $>5 \mathrm{~mm}$ ) [69]. A more recent 2011 prospective randomized phase III trial by Yang et al. compared CRS alone versus CRS and HIPEC with mitomycin $C$ and cisplatin for peritoneal carcinomatosis secondary to gastric cancer in patients with both similar PCI and CCR scores. Results demonstrated that CRS and HIPEC significantly improved survival by nearly $70 \%$ (6.5 vs. 11.0 months) compared with CRS alone $(p=0.046)$ [61]. Subsequently, the prospective CYTO-CHIP study in France confirmed the benefit of HIPEC in gastric peritoneal carcinomatosis in the Western population with a 5-year OS of $19.9 \%$ for patients treated with CRS and HIPEC $(n=180)$ versus $6.4 \%$ for those treated with CRS alone $(n=97)$ [73]. As large prospective randomized trials are lacking in Western patients, the GASTRICHIP trial is being undertaken in France. Over 300 patients will be randomized intraoperatively to receive gastric resection with or without HIPEC with Oxaliplatin, with a primary outcome of 5-year OS. Quality of life outcomes will also be evaluated [9].

Several studies have demonstrated that when PCI is higher than 12, survival remains poor, even with a complete cytoreduction. Indeed, in 1996 Fujimoto et al. reported a 5-year survival of 40-50\% for patients with limited peritoneal metastases, but a 1-year survival of only $18 \%$ for patients with numerous distant peritoneal metastases, according to the classification system by the Japanese Research Society for Gastric Cancer [68,74]. More recently, Glehen et al. reported that PCI is the most important prognostic factor in patients who are able to undergo complete CRS. The results of their randomized controlled trial demonstrated that no patient was alive at 6 months if they had a PCI greater than 19 and none at 3 years if they had a PCI greater than 12 [37]. Therefore, CRS and HIPEC should be carefully considered for patients with a PCI of 12 of lower to ensure a therapeutic benefit. Lastly, given the associated morbidity of CRS, patient selection is paramount and should take into account pre-operative functional status.

\subsection{Early Post-Operative Intraperitoneal Chemotherapy (EPIC)}

Early post-operative intraperitoneal chemotherapy has been proposed as a strategy to eliminate residual microscopic peritoneal disease after resection of stage III gastric cancer. EPIC regimens comprising either mitomycin $\mathrm{C}$ and 5-FU or taxanes are usually administered on post-operative days 1-5 through inflow and outflow catheters which are inserted at the time of CRS with repeated instillations every 24 hours. EPIC is administered early in the post-operative period prior to adhesion formation to optimize uniform distribution of the intraperitoneal agents [75]. Three studies have evaluated the use of EPIC after resection of gastric cancer.

$\mathrm{Yu}$ et al. compared curative gastric resection with or without EPIC with mitomycin C and 5-FU. The addition of EPIC after gastric resection resulted in improved 5-year OS compared to surgery alone ( $54 \%$ vs. $38 \%)$. In patients with stage III and stage IV disease, there was a significant increase of 5-year OS (stage III: $57 \%$ vs. $23 \%, p=0.0098$ and stage IV: $28 \%$ and $5 \%, p=0.0098$ ) in the EPIC group [76]. In a retrospective study by Kwon et al., 245 patients with stage III, serosa-invading, gastric cancer underwent either curative resection alone $(n=180)$ or curative resection and EPIC $(n=65)$. The 5 -year OS was $47.4 \%$ in the EPIC group and $26.7 \%$ in the non-EPIC group $(p=0.012)$ while the 5-year DSS rates were $53.1 \%$ in the EPIC group compared to $29.7 \%$ in the non-EPIC group $(p=0.011)$. Peritoneal recurrence rates for the EPIC group and the non-EPIC group were $18.5 \%$ and $32.2 \%$, respectively $(p=0.038)$ [77]. EPIC is being further evaluated in the Korean EPIC-GC trial (NCT02205008) where patients with gastric adenocarcinoma who are candidates for curative D2 resection of the stomach are randomized to either EPIC (mitomycin C and 5-FU) and adjuvant systemic chemotherapy employing S1 or adjuvant systemic chemotherapy with S1 alone. The primary end point is 3-year PFS. We currently await results from this trial which finalized accrual in late 2018. In the 
meantime, the addition of EPIC to CRS/HIPEC can be considered in patients with good performance status who are able to undergo a complete cytoreduction with no prior extensive pre-treatment.

\subsection{HIPEC as Palliative Approach}

One of the most frequent and debilitating complications of peritoneal carcinomatosis is the accumulation of malignant ascites which can result in a multitude of symptoms including abdominal pain, shortness of breath, early satiety in addition to fatigue, depression and anxiety [78]. The etiology of malignant ascites is complex and caused by the combined effects of tumor-produced proteins and impaired lymphatic drainage [79]. Although frequent paracentesis can help palliate symptoms, the effects only last approximately 72 hours, thus providing limited improvement to a patient's quality of life [80]. HIPEC has, therefore, been employed to decrease re-accumulation of ascites. Some of the first studies to report successful results were performed by Fujimoto et al. and Yonemura et al. with resolution of ascites in nearly $78 \%$ of patients $[81,82]$. Recently, laparoscopic HIPEC has also shown promising results for the treatment of malignant ascites as it reduces operative time and hospital length of stay. In a systematic review involving 76 patients who underwent palliative laparoscopic HIPEC, ascites control was achieved in $95 \%$ patients with no major complications and a $7.6 \%$ incidence of minor complications [82].

Although palliative CRS addresses the underlying tumor burden, morbidity is high and recovery is long thus limiting its indications. A 2014 retrospective review of 299 prospectively maintained CRS/HIPEC procedures performed for patients with ascites from various primary tumors (gastric adenocarcinoma: $6 \%$ ) found that CRS/HIPEC is $93 \%$ effective in successfully controlling ascites at three-month follow-up even when a complete cytoreduction is not achieved [83]. Although not explicitly published in this study, the resolution of ascites has been found to persist until death due to progressive disease [84]. These data suggest that palliative CRS/HIPEC may be effective in gastric cancer. However, more robust studies are needed to establish this technique in routine clinical practice.

\section{Future Areas of Study}

The data presented here provide a foundation on which to develop more prospective trials, particular in Western populations, to justify the inclusion of CRS and HIPEC in national treatment guidelines. Many questions remain to be addressed including the optimal intraperitoneal chemotherapy agent and dosing, the optimal timing and sequence of intraperitoneal chemotherapy, strategies to further reduce morbidity and the patient population who will most benefit from these interventions. Currently, various trials are ongoing in Europe and China using varying doses and dwelling time of oxaliplatin, oxaliplatin and paclitaxel, and mitomycin and cisplatin for peritoneal carcinomatosis or prophylactic HIPEC for locally advanced gastric cancer (Table 3).

As the research to answer these questions continues, new intraperitoneal techniques are being developed to help address some of the shortcomings of HIPEC and EPIC and expand the patient population eligible for these procedures. Pressurized intraperitoneal chemotherapy (PIPAC) is a new technique that uses aerosolized chemotherapy to produce a high tumor drug concentration and deeper penetration. During PIPAC, laparoscopic access is obtained to create a pneumoperitoneum of $12 \mathrm{~mm} \mathrm{Hg}$ and nebulized chemotherapy is given to create capnoperitoneum which is maintained for 30 minutes [85]. The increase in intra-abdominal pressure is thought to aid tissue uptake and intra-tumoral drug concentration [86]. An ongoing German trial (PIPAC GA-01; NCT01854255) is studying the clinical benefits of PIPAC (cisplatin and doxorubicin) in patients with recurrent gastric cancer. PIPAC is currently used for symptom palliation, but more evidence is needed before its indications can be expanded.

One of the challenges of intraperitoneal therapy is the delivery of sufficiently high intraperitoneal drug concentrations to provide a large concentration gradient between the peritoneal cavity and tumor tissue. Several drug-delivery systems such as nanoparticles, microspheres and hydrogels, are currently being developed and tested in order to maximize peritoneal concentration while 
continuing to minimize systemic toxicity [87]. Various immunotherapies are also being evaluated for intraperitoneal use including immune checkpoint inhibitors, chimeric antigen receptor-T cells (CAR-T Cells), and bevacizumab [88-90]. Catumaxomab, a rat-mouse hybrid monoclonal antibody, is a new agent that is being evaluated in phase II/III trials for use in patients with malignant ascites from gastric cancer after two recent studies demonstrated promising results [91,92]. One study showed an acceptable safety profile with minimal adverse events including fever, vomiting, and abdominal pain [91]. In the second phase II/III trial, patients with recurrent symptomatic malignant ascites were randomized to paracentesis plus intraperitoneal catumaxomab or paracentesis alone. Puncture-free survival was significantly longer in the catumaxomab group compared to the control group (median 46 vs. 11 days, HR: $0.254, p<0.0001$ ). Additionally, catumaxomab patients had fewer signs and symptoms of ascites than control patients [92]. Selecting the patients who will benefit most from these therapies will largely depend on the development of personalized approaches as we continue to identify ways to detect molecular alterations in tumor tissue via next-generation sequencing. Cell-free circulating tumor DNA in patients with peritoneal metastases has the potential to help disease prognostication and further identify optimal therapeutic strategies [93].

\section{Conclusions}

Current studies demonstrate that there is an emerging role for the use of prophylactic HIPEC to prevent the incidence of peritoneal metastases for high-risk patients with gastric cancer. Identification of patients with gastric cancer at high risk of developing peritoneal metastasis, standardization of the drugs and their dosage, and robust results from ongoing trials will ensure its inclusion in the treatment armamentarium for resectable gastric cancer.

For patients with established peritoneal carcinomatosis, current approaches for intraperitoneal chemotherapy include the use of NIPS, as curative-intent in both cytology-positive and macroscopic disease, and as EPIC in the setting of microscopic residual disease. The efficacy of these approaches relies on the possibility of achieving complete cytoreduction due to the limited drug action on a residual tumor nodules larger than $2.5 \mathrm{~mm}$ (CC0-1) [94]. Confirmation of burden of disease as measured by the PCI should be obtained with high-quality cross-sectional imaging, although diagnostic laparoscopy can also be used as a tool to evaluate the extent of peritoneal disease. Given study findings that demonstrate a benefit in survival, CRS/HIPEC is currently the optimal treatment in carefully selected patients with peritoneal carcinomatosis from gastric cancer origin with a $\mathrm{PCI}<12$. More studies are needed to further establish EPIC as a viable therapeutic strategy as the clinical data reporting the benefit of EPIC for gastric cancer is lacking and its current role remains undefined. Further research on the use of EPIC for gastric cancer should focus on the duration of drug instillation and number of cycles needed to result in improved long-term outcomes. There is still very limited data on the use of HIPEC as palliative approach for malignant ascites, though some studies suggest that it may be effective in gastric cancer. As such, the use of this technique is currently not established in clinical practice. Lastly, the therapeutic landscape for the treatment of peritoneal carcinomatosis continues to evolve with the development of new drugs and delivery systems as well as new techniques, such as PIPAC, which are actively being evaluated in clinical trials. Progress in the field of CRS and intraperitoneal chemotherapy will depend of effective collaboration between clinicians of various specialties and between institutions worldwide. Currently, there is a lack of large-scale, multi-institutional phase III trials to further assess the value of HIPEC in patients with gastric cancer likely because of the difficulty of performing these trials due to variability in surgeons' styles, perioperative care, and lack of standardization for the delivery of intraperitoneal chemotherapy. Although accrual of sufficient patients in these trials remains a challenge, the recently reported results from the PRODIGE-7 trial in colorectal cancer confirm that large-scale prospective trials in the field of HIPEC are feasible [95]. 
Table 3. Active gastric cancer CRS and HIPEC clinical trials.

\begin{tabular}{|c|c|c|c|c|c|c|}
\hline Trial & Country & $n$ & Treatment & Agent & $\begin{array}{c}\text { Primary } \\
\text { Endpoint }\end{array}$ & $\begin{array}{c}\text { Estimated } \\
\text { Completion }\end{array}$ \\
\hline NCT03092518 & USA & 40 & CRS + HIPEC & $\begin{array}{l}\text { Cisplatin + mitomycin C } \\
+ \text { sodium thiosulfate }\end{array}$ & Overall survival & October 2020 \\
\hline NCT02356276 & China & 584 & $\begin{array}{l}\text { CRS + post-operative HIPEC + systemic chemotherapy } \\
\text { vs. CRS alone + systemic chemotherapy }\end{array}$ & Paclitaxel & Overall survival & January 2022 \\
\hline NCT02891447 & USA & 30 & CRS + HIPEC & Mitomycin C + Cisplatin & Overall survival & September 2021 \\
\hline NCT02158988 & Germany & 180 & $\begin{array}{l}\text { Neoadjuvant chemotherapy + CRS + HIPEC vs. } \\
\text { neoadjuvant chemotherapy + CRS alone }\end{array}$ & Mitomycin C + Cisplatin & Overall survival & September 2020 \\
\hline NCT02960061 & China & 640 & $\begin{array}{l}\text { Neoadjuvant chemotherapy }+ \text { CRS }+ \text { HIPEC }+ \\
\text { adjuvant chemotherapy vs. neoadjuvant chemotherapy } \\
+ \text { CRS + adjuvant chemotherapy }\end{array}$ & Paclitaxel & Overall survival & December 2019 \\
\hline NCT03023436 & China & 220 & $\begin{array}{c}\text { CRS + HIPEC + systemic chemotherapy vs. systemic } \\
\text { chemotherapy alone }\end{array}$ & $\begin{array}{l}\text { Cisplatin }+ \\
\text { Fluoropyrimidine }\end{array}$ & Median survival & June 2022 \\
\hline NCT02969122 & China & 59 & $\begin{array}{c}\text { Neoadjuvant HIPEC + neoadjuvant chemotherapy } \pm \\
\text { CRS vs. CRS + HIPEC + adjuvant chemotherapy }\end{array}$ & Docetaxel & Overall survival & December 2023 \\
\hline NCT02381847 & China & 60 & CRS + HIPEC vs. CRS alone + adjuvant chemotherapy & Cisplatin & Overall survival & March 2020 \\
\hline NCT01882933 & France & 322 & CRS + HIPEC vs. CRS alone & Oxaliplatin & Overall survival & May 2025 \\
\hline
\end{tabular}


Funding: This research received no external funding and is supported in part by the Katz Foundation.

Conflicts of Interest: The authors declare no conflict of interest.

\section{References}

1. Bray, F.; Ferlay, J.; Soerjomataram, I.; Siegel, R.L.; Torre, L.A.; Jemal, A. Global Cancer Statistics 2018: GLOBOCAN Estimates of Incidence and Mortality Worldwide for 36 Cancers in 185 Countries. CA Cancer J. Clin. 2018, 6868, 394-424. [CrossRef] [PubMed]

2. Torre, L.A.; Siegel, R.L.; Ward, E.M.; Jemal, A. Global Cancer Incidence and Mortality Rates and Trends-An Update. Cancer Epidemiol. Biomark Prev. 2016, 25, 16-27. [CrossRef] [PubMed]

3. SEER Cancer Stat Facts: Stomach Cancer. Available online: https://seer.cancer.gov/statfacts/html/stomach. html (accessed on 10 October 2019).

4. Amin, M.B.; Greene, F.L.; Edge, S.B.; Compton, C.C.; Gershenwald, J.E.; Brookland, R.K.; Meyer, L.; Gress, D.M.; Byrd, D.R.; Winchester, D.P. The Eighth Edition AJCC Cancer Staging Manual: Continuing to build a bridge from a population-based to a more "personalized" approach to cancer staging. CA Cancer J. Clin. 2017, 67, 93-99. [CrossRef] [PubMed]

5. Bentrem, D.; Wilton, A.; Mazumdar, M.; Brennan, M.; Coit, D. The Value of Peritoneal Cytology as a Preoperative Predictor in Patients with Gastric Carcinoma Undergoing a Curative Resection. Ann. Surg. Oncol. 2005, 12, 347-353. [CrossRef] [PubMed]

6. Ikeguchi, M.; Oka, A.; Tsujitani, S.; Maeta, M.; Kaibara, N. Relationship between Area of Serosal Invasion and Intraperitoneal Free Cancer Cells in Patients with Gastric Cancer. Anticancer Res. 1994, 14, 2131-2134. [PubMed]

7. Fujimoto, S.; Takahashi, M.; Mutou, T.; Kobayashi, K.; Toyosawa, T. Successful Intraperitoneal Hyperthermic Chemoperfusion for the Prevention of Postoperative Peritoneal Recurrence in Patients with Advanced Gastric Carcinoma. Cancer 1999, 85, 529-534. [CrossRef]

8. Wu, C.W.; Lo, S.S.; Shen, K.H.; Hsieh, M.C.; Chen, J.H.; Chiang, J.H.; Lin, H.J.; Li, A.F.; Lui, W.Y. Incidence and Factors Associated with Recurrence Patterns after Intended Curative Surgery for Gastric Cancer. World J. Surg. 2003, 27, 153-158.

9. Glehen, O.; Passot, G.; Villeneuve, L.; Vaudoyer, D.; Bin-Dorel, S.; Boschetti, G.; Piaton, E.; Garofalo, A. GASTRICHIP: D2 Resection and Hyperthermic Intraperitoneal Chemotherapy in Locally Advanced Gastric Carcinoma: A Randomized and Multicenter Phase III Study. BMC Cancer 2014, 14, 183. [CrossRef]

10. Bonenkamp, J.J.; Songun, I.; Hermans, J.; van de Velde, C.J. Prognostic Value of Positive Cytology Findings from Abdominal Washings in Patients with Gastric Cancer. Br. J. Surg. 1996, 83, 672-674. [CrossRef]

11. Boku, T.; Nakane, Y.; Minoura, T.; Takada, H.; Yamamura, M.; Hioki, K.; Yamamoto, M. Prognostic Significance of Serosal Invasion and Free Intraperitoneal Cancer Cells in Gastric Cancer. Br. J. Surg. 1990, 77, 436-439. [CrossRef]

12. Yonemura, Y.; Elnemr, A.; Endou, Y.; Ishibashi, H.; Mizumoto, A.; Miura, M.; Li, Y. Effects of Neoadjuvant Intraperitoneal/Systemic Chemotherapy (Bidirectional Chemotherapy) for the Treatment of Patients with Peritoneal Metastasis from Gastric Cancer. Int. J. Surg. Oncol. 2012, 2012, 148420. [CrossRef] [PubMed]

13. Brucher, B.L.; Piso, P.; Verwaal, V.; Esquivel, J.; Derraco, M.; Yonemura, Y.; Gonzalez-Moreno, S.; Pelz, J.; Konigsrainer, A.; Strohlein, M.; et al. Peritoneal Carcinomatosis: Cytoreductive Surgery and HIPEC-Overview and Basics. Cancer Investig. 2012, 30, 209-224. [CrossRef] [PubMed]

14. Mezhir, J.J.; Shah, M.A.; Jacks, L.M.; Brennan, M.F.; Coit, D.G.; Strong, V.E. Positive Peritoneal Cytology in Patients with Gastric Cancer: Natural History and Outcome of 291 Patients. Indian J. Surg. Oncol. 2011, 2, 16-23. [CrossRef] [PubMed]

15. Maeda, H.; Kobayashi, M.; Sakamoto, J. Evaluation and Treatment of Malignant Ascites Secondary to Gastric Cancer. World J. Gastroenterol. 2015, 21, 10936-10947. [CrossRef]

16. National Comprehensive Cancer Network (NCCN). Available online: https://www.nccn.org/professionals/ physician_gls/default.aspx (accessed on 18 October 2019).

17. Landry, J.; Tepper, J.E.; Wood, W.C.; Moulton, E.O.; Koerner, F.; Sullinger, J. Patterns of Failure Following Curative Resection of Gastric Carcinoma. Int. J. Radiat. Oncol. Biol. Phys. 1990, 19, 1357-1362. [CrossRef]

18. Al-Batran, S.-E.; Lorenzen, S. Management of Locally Advanced Gastroesophageal Cancer: Still a Multidisciplinary Global Challenge? Hematol./Oncol. Clin. 2017, 31, 441-452. [CrossRef] 
19. Cunningham, D.; Allum, W.H.; Stenning, S.P.; Thompson, J.N.; Van de Velde, C.J.; Nicolson, M.; Scarffe, J.H.; Lofts, F.J.; Falk, S.J.; Iveson, T.J.; et al. Perioperative Chemotherapy Versus Surgery Alone for Resectable Gastroesophageal Cancer. N. Engl. J. Med. 2006, 355, 11-20. [CrossRef]

20. Al-Batran, S.E.; Homann, N.; Pauligk, C.; Goetze, T.O.; Meiler, J.; Kasper, S.; Kopp, H.G.; Mayer, F.; Haag, G.M.; Luley, K.; et al. Perioperative Chemotherapy with Fluorouracil Plus Leucovorin, Oxaliplatin, and Docetaxel Versus Fluorouracil or Capecitabine Plus Cisplatin and Epirubicin for Locally Advanced, Resectable Gastric or Gastro-Oesophageal Junction Adenocarcinoma (FLOT4): A Randomised, Phase 2/3 Trial. Lancet 2019, 393, 1948-1957.

21. Ronellenfitsch, U.; Schwarzbach, M.; Hofheinz, R.; Kienle, P.; Kieser, M.; Slanger, T.E.; Jensen, K. Perioperative Chemo(Radio)Therapy Versus Primary Surgery for Resectable Adenocarcinoma of the Stomach, Gastroesophageal Junction, and Lower Esophagus. Cochrane Database Syst. Rev. 2013, 5, Cd008107. [CrossRef]

22. Fujitani, K. Overview of Adjuvant and Neoadjuvant Therapy for Resectable Gastric Cancer in the East. Dig. Surg. 2013, 30, 119-129. [CrossRef]

23. Japanese Gastric Cancer Association. Japanese Gastric Cancer Treatment Guidelines 2014 (ver. 4). Gastric Cancer 2017, 20, 1-19. [CrossRef] [PubMed]

24. Sakuramoto, S.; Sasako, M.; Yamaguchi, T.; Kinoshita, T.; Fujii, M.; Nashimoto, A.; Furukawa, H.; Nakajima, T.; Ohashi, Y.; Imamura, H.; et al. Adjuvant Chemotherapy for Gastric Cancer with S-1, an Oral Fluoropyrimidine. N. Engl. J. Med. 2007, 357, 1810-1820. [CrossRef] [PubMed]

25. Cabalag, C.S.; Chan, S.T.; Kaneko, Y.; Duong, C.P. A Systematic Review and Meta-Analysis of Gastric Cancer Treatment in Patients with Positive Peritoneal Cytology. Gastric Cancer 2015, 18, 11-22. [CrossRef] [PubMed]

26. Bang, Y.J.; Kim, Y.W.; Yang, H.K.; Chung, H.C.; Park, Y.K.; Lee, K.H.; Lee, K.W.; Kim, Y.H.; Noh, S.I.; Cho, J.Y.; et al. Adjuvant Capecitabine and Oxaliplatin for Gastric Cancer after D2 Gastrectomy (CLASSIC): A Phase 3 Open-Label, Randomised Controlled Trial. Lancet 2012, 379, 315-321. [CrossRef]

27. Noh, S.H.; Park, S.R.; Yang, H.-K.; Chung, H.C.; Chung, I.-J.; Kim, S.-W.; Kim, H.-H.; Choi, J.-H.; Kim, H.-K.; $\mathrm{Yu}, \mathrm{W}$; ; et al. Adjuvant Capecitabine plus Oxaliplatin for Gastric Cancer after D2 Gastrectomy (CLASSIC): 5-year Follow-Up of an Open-Label, Randomised Phase 3 Trial. Lancet Oncol. 2014, 15, 1389-1396. [CrossRef]

28. Paoletti, X.; Oba, K.; Burzykowski, T.; Michiels, S.; Ohashi, Y.; Pignon, J.P.; Rougier, P.; Sakamoto, J.; Sargent, D.; Sasako, M.; et al. Benefit of Adjuvant Chemotherapy for Resectable Gastric Cancer: A Meta-Analysis. Jama 2010, 303, 1729-1737.

29. De Vita, F.; Giuliani, F.; Orditura, M.; Maiello, E.; Galizia, G.; Di Martino, N.; Montemurro, F.; Cartenì, G.; Manzione, L.; Romito, S.; et al. Adjuvant Chemotherapy with Epirubicin, Leucovorin, 5-fluorouracil and Etoposide Regimen in Resected Gastric Cancer Patients: A Randomized Phase III Trial by the Gruppo Oncologico Italia Meridionale (GOIM 9602 Study). Ann. Oncol. 2007, 18, 1354-1358. [CrossRef]

30. Cascinu, S.; Labianca, R.; Barone, C.; Santoro, A.; Carnaghi, C.; Cassano, A.; Beretta, G.D.; Catalano, V.; Bertetto, O.; Barni, S. Adjuvant treatment of high-risk, radically resected gastric cancer patients with 5-fluorouracil, leucovorin, cisplatin, and epidoxorubicin in a randomized controlled trial. J. Nat. Cancer Inst. 2007, 99, 601-607. [CrossRef]

31. Nitti, D.; Wils, J.; Dos Santos, J.G.; Fountzilas, G.; Conte, P.F.; Sava, C.; Tres, A.; Coombes, R.C.; Crivellari, D.; Marchet, A.; et al. Randomized Phase III Trials of Adjuvant FAMTX or FEMTX Compared with Surgery Alone in Resected Gastric Cancer. A Combined Analysis of the EORTC GI Group and the ICCG. Ann. Oncol. 2005, 17, 262-269. [CrossRef]

32. Choi, A.H.; Kim, J.; Chao, J. Perioperative Chemotherapy for Resectable Gastric Cancer: MAGIC and Beyond. World J. Gastroenterol. 2015, 21, 7343-7348. [CrossRef]

33. Macdonald, J.S.; Smalley, S.R.; Benedetti, J.; Hundahl, S.A.; Estes, N.C.; Stemmermann, G.N.; Haller, D.G.; Ajani, J.A.; Gunderson, L.L.; Jessup, J.M.; et al. Chemoradiotherapy after Surgery Compared with Surgery Alone for Adenocarcinoma of the Stomach or Gastroesophageal Junction. N. Engl. J. Med. 2001, 345, 725-730. [CrossRef] [PubMed]

34. Lee, J.; Lim, D.H.; Kim, S.; Park, S.H.; Park, J.O.; Park, Y.S.; Lim, H.Y.; Choi, M.G.; Sohn, T.S.; Noh, J.H.; et al. Phase III Trial Comparing Capecitabine Plus Cisplatin Versus Capecitabine Plus Cisplatin with Concurrent Capecitabine Radiotherapy in Completely Resected Gastric Cancer with D2 Lymph Node Dissection: The ARTIST Trial. J. Clin. Oncol. 2012, 30, 268-273. [CrossRef] [PubMed] 
35. Dikken, J.L.; van Sandick, J.W.; Maurits Swellengrebel, H.A.; Lind, P.A.; Putter, H.; Jansen, E.P.; Boot, H.; van Grieken, N.C.; van de Velde, C.J.; Verheij, M.; et al. Neo-Adjuvant Chemotherapy Followed by Surgery and Chemotherapy or by Surgery and Chemoradiotherapy for Patients with Resectable Gastric Cancer (CRITICS). BMC Cancer 2011, 11, 329. [CrossRef] [PubMed]

36. Shen, P.; Stewart, J.H.T.; Levine, E.A. Cytoreductive Surgery and Hyperthermic Intraperitoneal Chemotherapy for Peritoneal Surface Malignancy: Overview and Rationale. Curr. Probl. Cancer 2009, 33, 125-141. [CrossRef] [PubMed]

37. Glehen, O.; Gilly, F.N.; Arvieux, C.; Cotte, E.; Boutitie, F.; Mansvelt, B.; Bereder, J.M.; Lorimier, G.; Quenet, F.; Elias, D.; et al. Peritoneal Carcinomatosis from Gastric Cancer: A Multi-Institutional Study of 159 Patients Treated by Cytoreductive Surgery Combined with Perioperative Intraperitoneal Chemotherapy. Ann. Surg. Oncol. 2010, 17, 2370-2377. [CrossRef]

38. Preusser, P.; Wilke, H.; Achterrath, W.; Fink, U.; Lenaz, L.; Heinicke, A.; Meyer, J.; Meyer, H.J.; Buente, H. Phase II Study with the Combination Etoposide, Doxorubicin, and Cisplatin in Advanced Measurable Gastric Cancer. J. Clin. Oncol. 1989, 7, 1310-1317. [CrossRef]

39. Ajani, J.A.; Ota, D.M.; Jessup, J.M.; Ames, F.C.; McBride, C.; Boddie, A.; Levin, B.; Jackson, D.E.; Roh, M.; Hohn, D. Resectable Gastric Carcinoma. An Evaluation of Preoperative and Postoperative Chemotherapy. Cancer 1991, 68, 1501-1506. [CrossRef]

40. Thomassen, I.; van Gestel, Y.R.; van Ramshorst, B.; Luyer, M.D.; Bosscha, K.; Nienhuijs, S.W.; Lemmens, V.E.; de Hingh, I.H. Peritoneal Carcinomatosis of Gastric Origin: A Population-Based Study on Incidence, Survival and Risk Factors. Int. J. Cancer 2014, 134, 622-628. [CrossRef]

41. Spratt, J.S.; Adcock, R.A.; Sherrill, W.; Travathen, S. Hyperthermic Peritoneal Perfusion System in Canines. Cancer Res. 1980, 40, 253-255.

42. Sugarbaker, P.H. Peritonectomy Procedures. Ann. Surg. 1995, 221, 29-42. [CrossRef]

43. Sugarbaker, P.H. Gastric Cancer: Prevention and Treatment of Peritoneal Metastases. J. Cancer Metastasis Treat. 2018, 4, 7. [CrossRef]

44. Yan, T.D.; Cao, C.Q.; Munkholm-Larsen, S. A Pharmacological Review on Intraperitoneal Chemotherapy for Peritoneal Malignancy. World J. Gastrointest. Oncol. 2010, 2, 109-116. [CrossRef] [PubMed]

45. Pestieau, S.R.; Belliveau, J.F.; Griffin, H.; Stuart, O.A.; Sugarbaker, P.H. Pharmacokinetics of Intraperitoneal Oxaliplatin: Experimental Studies. J. Surg. Oncol. 2001, 76, 106-114. [CrossRef]

46. Jacquet, P.; Sugarbaker, P.H. Clinical Research Methodologies in Diagnosis and Staging of Patients with Peritoneal Carcinomatosis. Cancer Treat. Res. 1996, 82, 359-374. [PubMed]

47. Koga, S.; Hamazoe, R.; Maeta, M.; Shimizu, N.; Murakami, A.; Wakatsuki, T. Prophylactic Therapy for Peritoneal Recurrence of Gastric Cancer by Continuous Hyperthermic Peritoneal Perfusion with Mitomycin C. Cancer 1988, 61, 232-237. [CrossRef]

48. Yonemura, Y.; Kawamura, T.; Bandou, E.; Takahashi, S.; Sawa, T.; Matsuki, N. Treatment of Peritoneal Dissemination from Gastric Cancer by Peritonectomy and Chemohyperthermic Peritoneal Perfusion. Br. J. Surg. 2005, 92, 370-375. [CrossRef] [PubMed]

49. Fujimura, T.; Yonemura, Y.; Nakagawara, H.; Kitagawa, H.; Fushida, S.; Nishimura, G.; Miyazaki, I.; Shibata, K. Subtotal Peritonectomy with Chemohyperthermic Peritoneal Perfusion for Peritonitis Carcinomatosa in Gastrointestinal Cancer. Oncol. Rep. 2000, 7, 809-814. [CrossRef] [PubMed]

50. Yonemura, Y.; de Aretxabala, X.; Fujimura, T.; Fushida, S.; Katayama, K.; Bandou, E.; Sugiyama, K.; Kawamura, T.; Kinoshita, K.; Endou, Y.; et al. Intraoperative Chemohyperthermic Peritoneal Perfusion as An Adjuvant to Gastric Cancer: Final Results of A Randomized Controlled Study. Hepato-Gastroenterology 2001, $48,1776-1782$.

51. Goodman, M.D.; McPartland, S.; Detelich, D.; Saif, M.W. Chemotherapy for Intraperitoneal Use: A Review of Hyperthermic Intraperitoneal Chemotherapy and Early Post-Operative Intraperitoneal Chemotherapy. J. Gastrointest. Oncol. 2016, 7, 45-57.

52. Badgwell, B.; Blum, M.; Das, P.; Estrella, J.; Wang, X.; Ho, L.; Fournier, K.; Royal, R.; Mansfield, P.; Ajani, J. Phase II Trial of Laparoscopic Hyperthermic Intraperitoneal Chemoperfusion for Peritoneal Carcinomatosis or Positive Peritoneal Cytology in Patients with Gastric Adenocarcinoma. Ann. Surg. Oncol. 2017, 24, 3338-3344. [CrossRef]

53. Jacquet, P.; Jelinek, J.S.; Steves, M.A.; Sugarbaker, P.H. Evaluation of Computed Tomography in Patients with Peritoneal Carcinomatosis. Cancer 1993, 72, 1631-1636. [CrossRef] 
54. Newhook, T.E.; Agnes, A.; Blum, M.; Estrella, J.S.; Das, P.; Ho, L.; Ajani, J.A.; Minsky, B.D.; Mansfield, P.; Badgwell, B.D. Laparoscopic Hyperthermic Intraperitoneal Chemotherapy is Safe for Patients with Peritoneal Metastases from Gastric Cancer and May Lead to Gastrectomy. Ann. Surg. Oncol. 2019, 26, 1394-1400. [CrossRef] [PubMed]

55. Yonemura, Y.; Bandou, E.; Sawa, T.; Yoshimitsu, Y.; Endou, Y.; Sasaki, T.; Sugarbaker, P.H. Neoadjuvant Treatment of Gastric Cancer with Peritoneal Dissemination. Eur. J. Surg. Oncol. 2006, 32, 661-665. [CrossRef] [PubMed]

56. Canbay, E.; Mizumoto, A.; Ichinose, M.; Ishibashi, H.; Sako, S.; Hirano, M.; Takao, N.; Yonemura, Y. Outcome Data of Patients with Peritoneal Carcinomatosis from Gastric Origin Treated by a Strategy of Bidirectional Chemotherapy Prior to Cytoreductive Surgery and Hyperthermic Intraperitoneal Chemotherapy in a Single Specialized Center in Japan. Ann. Surg. Oncol. 2014, 21, 1147-1152. [CrossRef]

57. Kim, J.Y.; Bae, H.S. A Controlled Clinical Study of Serosa-Invasive Gastric Carcinoma Patients who Underwent Surgery Plus Intraperitoneal Hyperthermo-Chemo-Perfusion (IHCP). Gastric Cancer 2001, 4, 27-33. [CrossRef]

58. Yan, T.D.; Black, D.; Sugarbaker, P.H.; Zhu, J.; Yonemura, Y.; Petrou, G.; Morris, D.L. A Systematic Review and Meta-Analysis of the Randomized Controlled Trials on Adjuvant Intraperitoneal Chemotherapy for Resectable Gastric Cancer. Ann. Surg. Oncol. 2007, 14, 2702-2713. [CrossRef]

59. Coccolini, F.; Cotte, E.; Glehen, O.; Lotti, M.; Poiasina, E.; Catena, F.; Yonemura, Y.; Ansaloni, L. Intraperitoneal Chemotherapy in Advanced Gastric Cancer. Meta-Analysis of Randomized Trials. Eur. J. Surg. Oncol. 2014, 40, 12-26. [CrossRef]

60. Desiderio, J.; Chao, J.; Melstrom, L.; Warner, S.; Tozzi, F.; Fong, Y.; Parisi, A.; Woo, Y. The 30-year Experience-A Meta-Analysis of Randomised and High-Quality Non-Randomised Studies of Hyperthermic Intraperitoneal Chemotherapy in the Treatment of Gastric Cancer. Eur. J. Cancer 2017, 79, 1-14. [CrossRef]

61. Hamazoe, R.; Maeta, M.; Kaibara, N. Intraperitoneal Thermochemotherapy for Prevention of Peritoneal Recurrence of Gastric Cancer. Final Results of a Randomized Controlled Study. Cancer 1994, 73, 2048-2052. [CrossRef]

62. Ikeguchi, M.; Kondou, A.; Oka, A.; Tsujitani, S.; Maeta, M.; Kaibara, N. Effects of Continuous Hyperthermic Peritoneal Perfusion on Prognosis of Gastric Cancer with Serosal Invasion. Eur. J. Surg. 1995, 161, 581-586.

63. Hirose, K.; Katayama, K.; Iida, A.; Yamaguchi, A.; Nakagawara, G.; Umeda, S.; Kusaka, Y. Efficacy of Continuous Hyperthermic Peritoneal Perfusion for the Prophylaxis and Treatment of Peritoneal Metastasis of Advanced Gastric Cancer: Evaluation by Multivariate Regression Analysis. Oncology 1999, 57, 106-114. [CrossRef] [PubMed]

64. Zhu, Z.G.; Tang, R.; Yan, M.; Chen, J.; Yang, Q.M.; Li, C.; Yao, X.X.; Zhang, J.; Yin, H.R.; Lin, Y.Z. Efficacy and Safety of Intraoperative Peritoneal Hyperthermic Chemotherapy for Advanced Gastric Cancer Patients with Serosal Invasion. A Long-Term Follow-Up Study. Dig. Surg. 2006, 23, 93-102. [CrossRef] [PubMed]

65. Fujimoto, S.; Shrestha, R.D.; Kokubun, M.; Kobayashi, K.; Kiuchi, S.; Konno, C.; Ohta, M.; Takahashi, M.; Kitsukawa, Y.; Mizutani, M.; et al. Positive Results of Combined Therapy of Surgery and Intraperitoneal Hyperthermic Perfusion for Far-Advanced Gastric Cancer. Ann. Surg. 1990, 212, 592-596. [CrossRef] [PubMed]

66. Yonemura, Y.; Fujimura, T.; Fushida, S.; Takegawa, S.; Kamata, T.; Katayama, K.; Kosaka, T.; Yamaguchi, A.; Miwa, K.; Miyazaki, I. Hyperthermo-Chemotherapy Combined with Cytoreductive Surgery for the Treatment of Gastric Cancer with Peritoneal Dissemination. World J. Surg. 1991, 15, 530-535. [CrossRef]

67. Yonemura, Y.; Fujimura, T.; Nishimura, G.; Falla, R.; Sawa, T.; Katayama, K.; Tsugawa, K.; Fushida, S.; Miyazaki, I.; Tanaka, M.; et al. Effects of Intraoperative Chemohyperthermia in Patients with Gastric Cancer with Peritoneal Dissemination. Surgery 1996, 119, 437-444. [CrossRef]

68. Fujimoto, S.; Takahashi, M.; Mutou, T.; Kobayashi, K.; Toyosawa, T.; Isawa, E.; Sumida, M.; Ohkubo, H. Improved Mortality Rate of Gastric Carcinoma Patients with Peritoneal Carcinomatosis Treated with Intraperitoneal Hyperthermic Chemoperfusion Combined with Surgery. Cancer 1997, 79, 884-891. [CrossRef]

69. Glehen, O.; Schreiber, V.; Cotte, E.; Sayag-Beaujard, A.C.; Osinsky, D.; Freyer, G.; Francois, Y.; Vignal, J.; Gilly, F.N. Cytoreductive Surgery and Intraperitoneal Chemohyperthermia for Peritoneal Carcinomatosis Arising from Gastric Cancer. Arch. Surg. 2004, 139, 20-26. [CrossRef]

70. Yang, X.J.; Li, Y.; Yonemura, Y. Cytoreductive Surgery Plus Hyperthermic Intraperitoneal Chemotherapy to Treat Gastric Cancer with Ascites and/or Peritoneal Carcinomatosis: Results from a Chinese Center. J. Surg. Oncol. 2010, 101, 457-464. [CrossRef] 
71. Yang, X.J.; Huang, C.Q.; Suo, T.; Mei, L.J.; Yang, G.L.; Cheng, F.L.; Zhou, Y.F.; Xiong, B.; Yonemura, Y.; Li, Y. Cytoreductive Surgery and Hyperthermic Intraperitoneal Chemotherapy Improves Survival of Patients with Peritoneal Carcinomatosis from Gastric Cancer: Final Results of a Phase III Randomized Clinical Trial. Ann. Surg. Oncol. 2011, 18, 1575-1581. [CrossRef]

72. Magge, D.; Zenati, M.; Mavanur, A.; Winer, J.; Ramalingam, L.; Jones, H.; Zureikat, A.; Holtzman, M.; Lee, K.; Ahrendt, S.; et al. Aggressive Locoregional Surgical Therapy for Gastric Peritoneal Carcinomatosis. Ann. Surg. Oncol. 2014, 21, 1448-1455. [CrossRef]

73. Bonnot, P.E.; Piessen, G.; Pocard, M.; Meunier, B.; Bereder, J.M.; Abboud, K.; Marchal, F.; Quenet, F.; Goere, D.; Msika, S.; et al. CYTO-CHIP: Cytoreductive Surgery Versus Cytoreductive Surgery and Hyperthermic Intraperitoneal Chemotherapy for Gastric Cancer with Peritoneal Metastasis: A Propensity-Score Analysis from BIG RENAPE and FREGAT Working Groups. J. Clin. Oncol. 2018, 36 (Suppl. 4), 8. [CrossRef]

74. Kajitani, T. The General Rules for the Gastric Cancer Study in Surgery and Pathology. Part I. Clinical Classification. Jpn. J. Surg. 1981, 11, 127-139. [PubMed]

75. Sugarbaker, P.H.; Graves, T.; DeBruijn, E.A.; Cunliffe, W.J.; Mullins, R.E.; Hull, W.E.; Oliff, L.; Schlag, P. Early Postoperative Intraperitoneal Chemotherapy as an Adjuvant Therapy to Surgery for Peritoneal Carcinomatosis from Gastrointestinal Cancer: Pharmacological Studies. Cancer Res. 1990, 50, 5790-5794. [PubMed]

76. Yu, W.; Whang, I.; Chung, H.Y.; Averbach, A.; Sugarbaker, P.H. Indications for Early Postoperative Intraperitoneal Chemotherapy of Advanced Gastric Cancer: Results of a Prospective Randomized Trial. World J. Surg. 2001, 25, 985-990. [CrossRef] [PubMed]

77. Kwon, O.K.; Chung, H.Y.; Yu, W. Early Postoperative Intraperitoneal Chemotherapy for Macroscopically Serosa-Invading Gastric Cancer Patients. Cancer Res. Treat. 2014, 46, 270-279. [CrossRef]

78. Husain, A.; Bezjak, A.; Easson, A. Malignant Ascites Symptom Cluster in Patients Referred for Paracentesis. Ann. Surg. Oncol. 2010, 17, 461-469. [CrossRef]

79. Garrison, R.N.; Kaelin, L.D.; Galloway, R.H.; Heuser, L.S. Malignant Ascites. Clinical and Experimental Observations. Ann. Surg. 1986, 203, 644-651. [CrossRef]

80. Sangisetty, S.L.; Miner, T.J. Malignant Ascites: A Review of Prognostic Factors, Pathophysiology and Therapeutic Measures. World J. Gastrointest. Surg. 2012, 4, 87-95. [CrossRef]

81. Fujimoto, S.; Shrestha, R.D.; Kokubun, M.; Ohta, M.; Takahashi, M.; Kobayashi, K.; Kiuchi, S.; Okui, K.; Miyoshi, T.; Arimizu, N.; et al. Intraperitoneal Hyperthermic Perfusion Combined with Surgery Effective for Gastric Cancer Patients with Peritoneal Seeding. Ann. Surg. 1988, 208, 36-41. [CrossRef]

82. Facchiano, E.; Risio, D.; Kianmanesh, R.; Msika, S. Laparoscopic Hyperthermic Intraperitoneal Chemotherapy: Indications, Aims, and Results: A Systematic Review of the Literature. Ann. Surg. Oncol. 2012, 19, 2946-2950. [CrossRef]

83. Randle, R.W.; Swett, K.R.; Swords, D.S.; Shen, P.; Stewart, J.H.; Levine, E.A.; Votanopoulos, K.I. Efficacy of Cytoreductive Surgery with Hyperthermic Intraperitoneal Chemotherapy in the Management of Malignant Ascites. Ann. Surg. Oncol. 2014, 21, 1474-1479. [CrossRef] [PubMed]

84. Katdare, N.; Probhu, R.; Bhatt, A. Locoregional and Palliative Therapies for Patients with Unresectable Peritoneal Metastases. Manage. Perit. Metastases-Cytoreductive Surg. Hipec Beyond 2018, 527-559.

85. Solaß, W.; Hetzel, A.; Nadiradze, G.; Sagynaliev, E.; Reymond, M.A. Description of a Novel Approach for Intraperitoneal Drug Delivery and the Related Device. Surg. Endosc. 2012, 26, 1849-1855.

86. Esquis, P.; Consolo, D.; Magnin, G.; Pointaire, P.; Moretto, P.; Ynsa, M.D.; Beltramo, J.-L.; Drogoul, C.; Simonet, M.; Benoit, L.; et al. High Intra-Abdominal Pressure Enhances the Penetration and Antitumor Effect of Intraperitoneal Cisplatin on Experimental Peritoneal Carcinomatosis. Ann. Surg. 2006, 244, 106-112. [CrossRef] [PubMed]

87. Chung, H.J.; Park, T.G. Self-Assembled and Nanostructured Hydrogels for Drug Delivery and Tissue Engineering. Nano Today 2009, 4, 429-437. [CrossRef]

88. Koneru, M.; Purdon, T.J.; Spriggs, D.; Koneru, S.; Brentjens, R.J. IL-12 Secreting Tumor-Targeted Chimeric Antigen Receptor T Cells Eradicate Ovarian Tumors in Vivo. Oncoimmunology 2015, 4, e994446. [CrossRef]

89. Numnum, T.M.; Rocconi, R.P.; Whitworth, J.; Barnes, M.N. The Use of Bevacizumab to Palliate Symptomatic Ascites in Patients with Refractory Ovarian Carcinoma. Gynecol. Oncol. 2006, 102, 425-428. [CrossRef]

90. El-Shami, K.; Elsaid, A.; El-Kerm, Y. Open-Label Safety and Efficacy Pilot Trial of Intraperitoneal Bevacizumab as Palliative Treatment in Refractory Malignant Ascites. J. Clin. Oncol. 2007, 25 (Suppl. 18), 9043. 
91. Strohlein, M.A.; Lordick, F.; Ruttinger, D.; Grutzner, K.U.; Schemanski, O.C.; Jager, M.; Lindhofer, H.; Hennig, M.; Jauch, K.W.; Peschel, C.; et al. Immunotherapy of Peritoneal Carcinomatosis with the Antibody Catumaxomab in Colon, Gastric, or Pancreatic Cancer: An Open-Label, Multicenter, Phase I/II Trial. Onkologie 2011, 34, 101-108. [CrossRef]

92. Heiss, M.M.; Murawa, P.; Koralewski, P.; Kutarska, E.; Kolesnik, O.O.; Ivanchenko, V.V.; Dudnichenko, A.S.; Aleknaviciene, B.; Razbadauskas, A.; Gore, M.; et al. The Trifunctional Antibody Catumaxomab for the Treatment of Malignant Ascites due to Epithelial Cancer: Results of a Prospective Randomized Phase II/III Trial. Int. J. Cancer 2010, 127, 2209-2221. [CrossRef]

93. Baumgartner, J.M.; Raymond, V.M.; Lanman, R.B.; Tran, L.; Kelly, K.J.; Lowy, A.M.; Kurzrock, R. Preoperative Circulating Tumor DNA in Patients with Peritoneal Carcinomatosis is an Independent Predictor of Progression-Free Survival. Ann. Surg. Oncol. 2018, 25, 2400-2408. [CrossRef] [PubMed]

94. Sugarbaker, P.H.; Landy, D.; Jaffe, G.; Pascal, R. Histologic Changes Induced by Intraperitoneal Chemotherapy with 5-fluorouracil and Mitomycin C in Patients with Peritoneal Carcinomatosis from Cystadenocarcinoma of the Colon or Appendix. Cancer 1990, 65, 1495-1501. [CrossRef]

95. Quenet, F.; Elias, D.; Roca, L.; Goere, D.; Ghouti, L.; Pocard, M.; Facy, O.; Arvieux, C.; Lorimier, G.; Pezet, D.; et al. A UNICANCER Phase III Trial of Hyperthermic Intra-Peritoneal Chemotherapy (HIPEC) for Colorectal Peritoneal Carcinomatosis (PC): PRODIGE 7. J. Clin. Oncol. 2018, 36 (Suppl. 18), 1. [CrossRef]

(C) 2019 by the authors. Licensee MDPI, Basel, Switzerland. This article is an open access article distributed under the terms and conditions of the Creative Commons Attribution (CC BY) license (http://creativecommons.org/licenses/by/4.0/). 